DOI: http://doi.org/10.21698/simi.2018.fp34

\title{
THE BEST PRACTICES FOR THE ASSESSMENT OF THE RAINWATER DRAINED BY THE URBAN SEWERAGE SYSTEMS
}

\author{
Daniel Scradeanu' ${ }^{1}$, Giuliano Tevi², Alexandru Balint $^{1}$ \\ ${ }^{1}$ University of Bucharest, 6 Traian Vuia, 020956, district 2, Bucharest, \\ daniel.scradeanu@gg.unibuc.ro, ioan.alexandru.balint@drd.unibuc.ro, Romania \\ ${ }^{2}$ Ecological University of Bucharest, 1G Vasile Milea, Bucharest, giuliano.tevi@ueb.ro, \\ Romania
}

\begin{abstract}
The current article includes a quantitative model which was developed based on the natural conditions of a specific site and it proposes an easily applicable methodology which allows estimates for: the quantity of rainwater collected by surface runoff; the quantity of rainwater collected by groundwater flow, due to the infiltration in aquifers; the quantity of rainwater collected by sewerage systems.

The case study was developed for a site located in the Pantelimon area (in eastern Bucharest) and it compares the results of the standardised model and quantitative model. Additionally, the article provides an interpretation of the differences obtained between the natural and anthropic site conditions.
\end{abstract}

Keywords: coupled model, standards, surface drainage, vadose zone

\section{Introduction}

The assessment of the rainwater drained by the sewerage systems in urban areas, specifically for Bucharest area, is currently conducted using a standardised model in accordance with the following regulation acts and standards:

- Ministry Order no. 88 from 20 March 2017 on the approval of the Framework Regulation for the water supply and sewerage services;

- $\quad S R$ 1846-1:2006 Sewages outside the buildings. Design specifications. Part 1: Calculation of sewerage flows;

- $\quad$ SR 1846-2:2007 Sewages outside the buildings. Design specifications. Part 2: Calculation of storm water flows. - standard which defines the runoff coefficients for each type of building;

- Decision of the Bucharest Local Council (HCLMB - acronym from Romanian language) no. 23/1993, considered for the case study, which defines the specific quantity of rainwater for the economical operators in Bucharest.

The standardised model is inaccurate and has a level of incertitude generated by the surface runoff and groundwater flow characteristics of the site. The current paper 


\section{INTERNATIONAL SYMPOSIUM "THE ENVIRONMENT AND THE INDUSTRY", SIMI 2018, PROCEEDINGS BOOK}

aims at identifying the differences between the rainwater drainage estimates through standardised model and the actual values calculated at a specific site level.

\section{Materials and Methods}

\section{Site Location}

The assessment was conducted on a site located in the eastern part of Bucharest, at 375 Soseaua Pantelimon, District 2 hereby referred to as "Faur site". The location of the site is depicted in Figure 1 below.

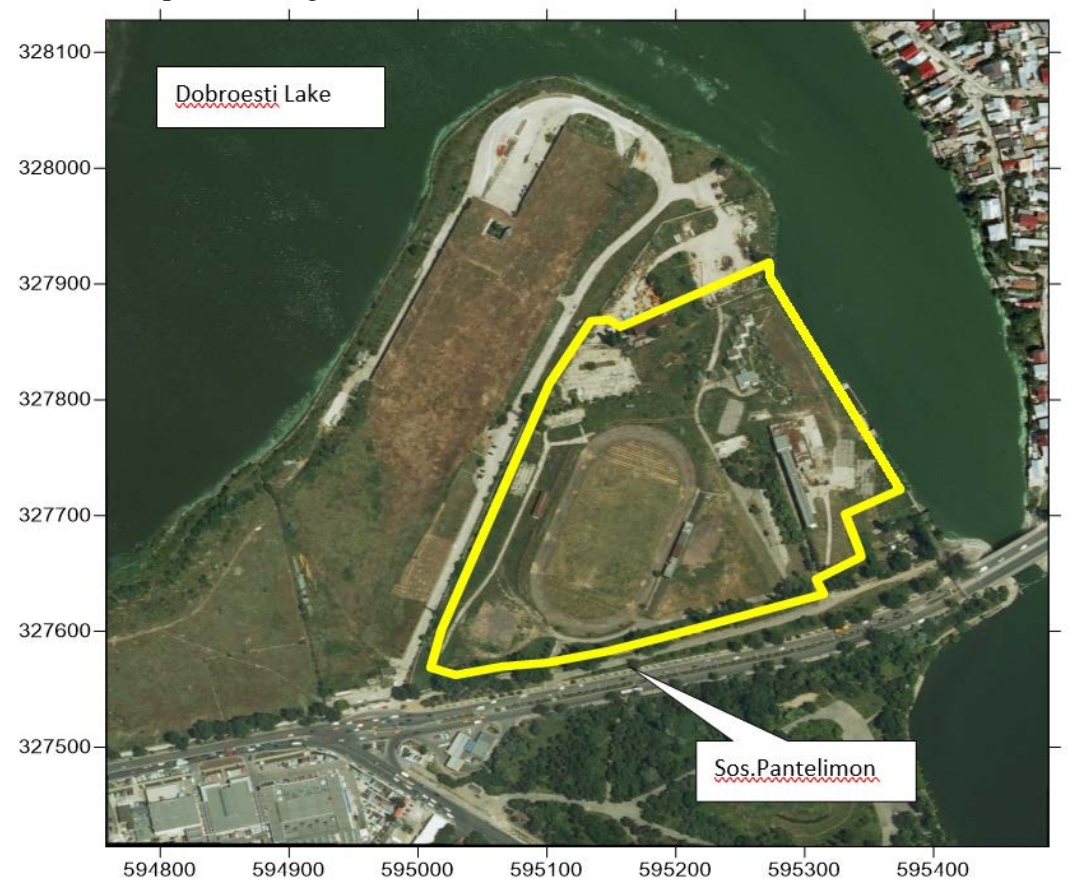

Figure 3. Location of the Faur site in the eastern part of Bucharest

The site is located on the second terrace of the Dambovita River and its northern boundary is delimited by the first terrace of the Colentina River. The relative altitude of the site with regard to the Colentina River is approximately 7-8 m.

In accordance with the Land Registry no. 203292, the site has a total area of $78,644.00 \mathrm{~m}^{2}$ divided as follows: constructed areas which comprise 1,642.21 $\mathrm{m}^{2}$ accounting $2 \%$ of the total site area and non-constructed areas which comprise $77,001.79 \mathrm{~m}^{2}$ accounting $98 \%$ of the total site area. 


\section{INTERNATIONAL SYMPOSIUM "THE ENVIRONMENT AND THE INDUSTRY", SIMI 2018, PROCEEDINGS BOOK}

\section{Methodology and Information Sources}

The assessment consisted in four stages as follows:

- $\quad$ Outlining the specific rainfall-associated characteristics of the site;

- Defining the surface runoff and groundwater flow of the site related to topography, geology and hydrogeology;

- Correlating the rainfall and the surface runoff and groundwater flow characteristics related to the existing sewerage systems;

- $\quad$ Comparing the results with the standardised calculation model.

The preliminary input data consisted of the following documents:

- $\quad$ Land Registry no. 203292, District 2, Bucharest containing data about the existing constructed and non-constructed areas of the Faur site;

- $\quad$ Land survey conducted between April 4 and 13, 2018. The purpose of the survey was to update the constructed and non-constructed surfaces with regard to the surface runoff and infiltration characteristics;

- Documentation which provided the information necessary for the surface runoff and groundwater flow assessment.

\section{Meteorological Information}

In order to estimate the surface runoff and groundwater flow characteristics, a hydrologic balance in terms of evapotranspiration, runoff and infiltration was defined using the following equation:

$$
\mathrm{P}=\mathrm{E}+\mathrm{Y}+\mathrm{I} \pm \text { storage }
$$

where $\mathrm{P}$ is precipitation, $\mathrm{E}$ is evapotranspiration estimated based on the temperature (T), $\mathrm{Y}$ is the runoff based on the evaluation of the slopes through the digital elevation model, I is the infiltration based on the permeability of the land cover, which is the main factor for groundwater flow and storage is lakes, pools and perched groundwater.

Table 1. Average values for temperature, humidity and rainfall for Bucharest

\begin{tabular}{c|ccc}
\hline Month & $\begin{array}{c}\text { Avg. temperature } \\
{\left[{ }^{\circ} \mathrm{C}\right]}\end{array}$ & $\begin{array}{c}\text { Avg. humidity } \\
{[\%]}\end{array}$ & $\begin{array}{c}\text { Avg. rainfall } \\
{[\mathrm{mm}]}\end{array}$ \\
\hline Jan & -3.0 & 87 & 46 \\
Feb & -0.5 & 84 & 26 \\
Mar & 4.5 & 73 & 28 \\
Apr & 11.5 & 63 & 59 \\
May & 16.5 & 63 & 77 \\
Jun & 20.5 & 62 & 121 \\
Jul & 23.0 & 58 & 53 \\
Aug & 22.5 & 59 & 45 \\
Sep & 18.0 & 63 & 45 \\
Oct & 12.0 & 73 & 29 \\
Nov & 6.0 & 85 & 36 \\
Dec & 0.5 & 89 & 27 \\
\hline
\end{tabular}




\section{INTERNATIONAL SYMPOSIUM "THE ENVIRONMENT AND THE INDUSTRY", SIMI 2018, PROCEEDINGS BOOK}

Precipitations were estimated by taking into account the monthly average values recorded in Bucharest for rainfall, temperature and relative humidity, which are depicted in Table 1.

Based on Table 1, the annual rainfall is approximately $600 \mathrm{~mm}$. According to the existing meteorological data, the minimum and maximum values for temperature recorded in Bucharest were $-32.2{ }^{\circ} \mathrm{C}$ recorded in January 25, 1942 at Bucharest Baneasa and $42.4{ }^{\circ} \mathrm{C}$ recorded in July 5, 2000 at Bucharest Filaret.

\section{Surface Runoff}

In order to estimate the surface runoff, a digital elevation model (DEM) was generated at a 20x20 m grid, which enabled to determine the flow direction of the runoff, which was depicted in Figure 2.

It can be observed that most of the surface water is directed outside the boundary of the site, except the runoff reaching two depressional areas located in the centre and south-western part of the site, the stadium and the tennis court, respectively.

The water accumulated in the two depressional areas stagnates and evaporates or it reaches the aquifer named "Colentina gravel" ("pietrisuri de Colentina" in Romanian) through infiltration, as described in the groundwater flow section.

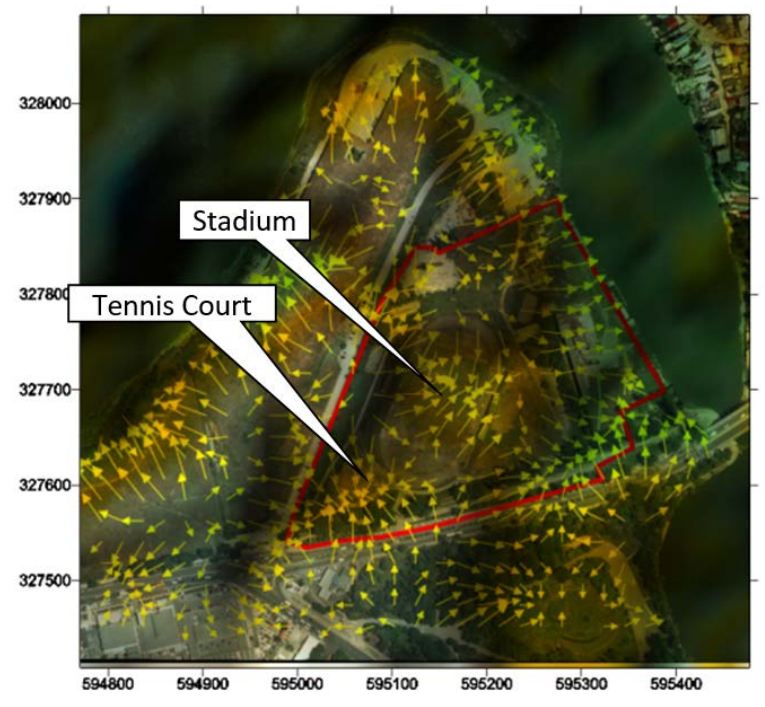

Figure 4. Surface drainage flow direction

The volume of the rainwater collected by the surface runoff (Y) is estimated as a difference between the precipitation $(\mathrm{P})$ and the annual real evapotranspiration ( $\left.\mathrm{E}_{\mathrm{ra}}\right)$ using the following equation: $Y=P-E_{r a}$

The annual real evapotranspiration is determined using the following equation (Castany 1972): 


$$
E_{r a}=\frac{X}{\sqrt{0.9+\frac{X^{2}}{L^{2}}}}[\mathrm{~mm} / \text { year }]
$$

where $L=300+25 \cdot T_{m}+0.05 \cdot T_{m}^{2}$, $\mathrm{X}$ is the annual rainfall [mm] and $T_{\mathrm{m}}$ is the annual average temperature calculated as a weighted average of the monthly precipitation with the following equation:

$$
T_{m}=\frac{X_{1} \cdot T_{1}+X_{2} \cdot T_{2}+\ldots+X_{12} \cdot T_{12}}{X_{1}+X_{2}+\ldots+X_{12}}
$$

It was determined that the annual real evapotranspiration for Bucharest area is 450 $\mathrm{mm} /$ year accounting for approximately $76 \%$ of the annual rainfall of $592 \mathrm{~mm} /$ year. Consequently, the maximum rate of rainwater collected by the surface runoff is the following:

$$
Y=P-E_{r a}=592-450=142 \frac{\mathrm{mm}}{\text { year }}=0.142 \frac{\mathrm{m}^{3}}{\mathrm{~m}^{2} \cdot \text { year }}
$$

Based on the land survey, runoff coefficients were established for each existing building and paved area based on the roof and drainage construction material in accordance with SR 18462:2007 as follows: 0.00 for areas with drainage outside the boundaries of the site, 0.05 for nonpaved areas, 0.85 for areas made out of asphalt and 0.95 for buildings with metal roofs.

The distribution of the maximum rate of rainwater is depicted in Figure 3.

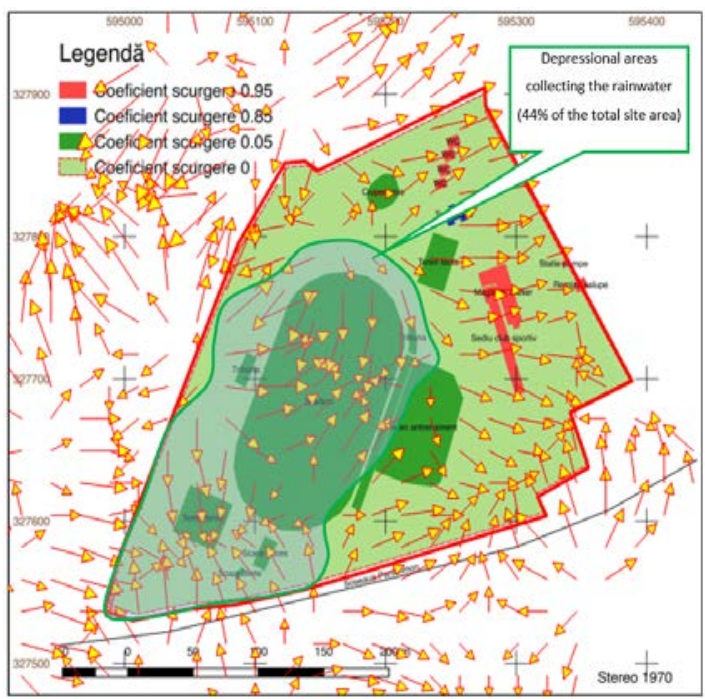

Figure 3. Distribution of the maximum rate of rainwater 


\section{INTERNATIONAL SYMPOSIUM "THE ENVIRONMENT AND THE INDUSTRY", SIMI 2018, PROCEEDINGS BOOK}

The figure highlights the following areas:

- Surface runoff - includes all constructed areas with a runoff coefficient of 0.85 and $0.95\left(44,041 \mathrm{~m}^{2}\right.$ accounting approximately $56 \%$ of the total site area);

- Water accumulation - includes horizontal and depressional areas with a runoff coefficient of 0.0 and 0.05 which enable the evaporation and infiltration (34,063 $\mathrm{m}^{2}$ accounting approximately $48 \%$ of the total site area);

- Infiltration in the "Colentina gravel" - includes horizontal and depressional areas with a runoff coefficient of 0.0 and $0.05\left(34,063 \mathrm{~m}^{2}\right.$ accounting approximately $48 \%$ of the total site area).

\section{Groundwater Flow}

The site overlaps the "Colentina gravel" aquifer, which collects the rainwater infiltrations from the plains of the Colentina River and Dambovita River. The aquifer has a maximum thickness of approximately 16-17 $\mathrm{m}$ in the centre of Bucharest and a minimum thickness of $1-2 \mathrm{~m}$ in the western part, below $3 \mathrm{~m}$ thickness in the north-western part and 0.5-1 m thickness under Fundeni and Pantelimon Lakes.

Based on the piezometric surface for the "Colentina gravel" aquifer, it was determined that the general groundwater flow is from NW to SE, with a groundwater head of $87 \mathrm{~m}$ AMSL to $52 \mathrm{~m}$ AMSL, respectively. The hydraulic gradients have values between 1.14-1.63\%. The piezometric surface map is depicted in Figure 4 and a cross-section through the location of the site is depicted in Figure 5.

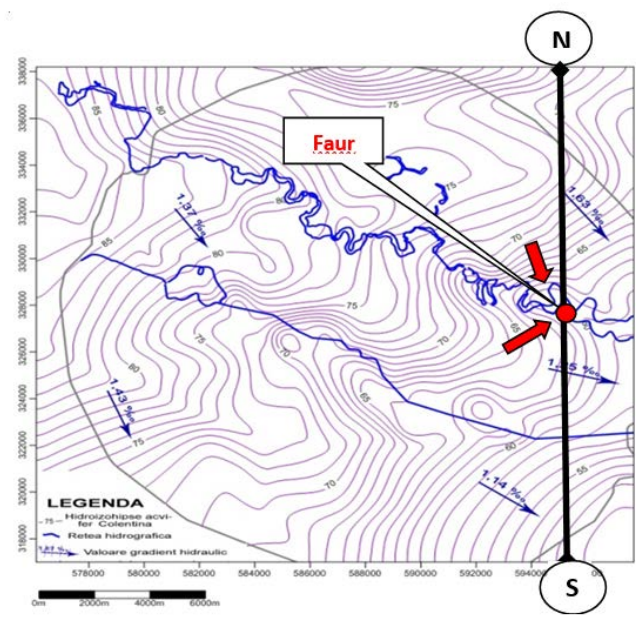

Figure 5. Piezometric surface of the "Colentina Gravel” aquifer 


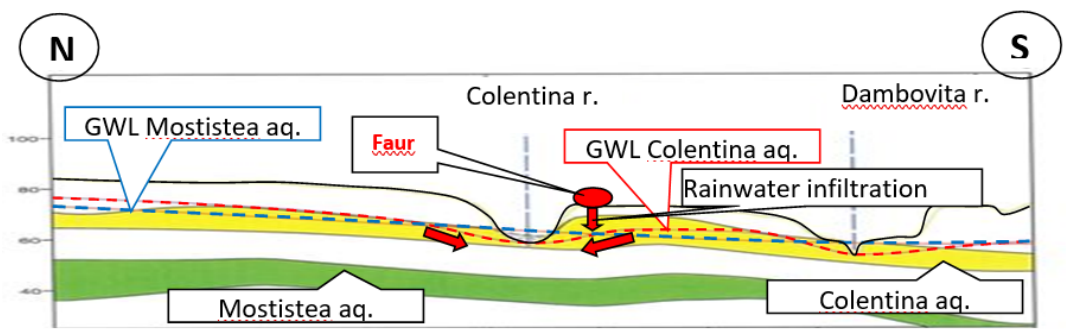

Figure 6. Cross-section through Faur site

Figure 5 depicts the fact that the "Colentina gravel" aquifer is drained by the Colentina River in the area of the Faur site. Consequently, the rainwater infiltrated over a surface of 34,063 $\mathrm{m}^{2}$ will reach the Colentina River.

\section{Standardised Model}

In accordance with the Ministry Order no. 88 from 20 March 2017 on the approval of the Framework Regulation for the water supply and sewerage services, Art. 215, the rainwater drained by the sewerage system is determined by multiplying the specific quantity of rainwater for the previous month provided by the National Administration for Meteorology (ANM - acronym from Romanian language) with the total areas of the constructed and non-constructed surfaces and with the runoff coefficients.

The quantity of rainwater drained by the sewerage systems using the standardised model is determined using the following equation:

$$
A M=q S \cdot \sum_{i=1}^{n} S_{i} \cdot C S_{i}
$$

where AM is the quantity of rainwater drained by the sewerage systems, qS is the specific quantity of rainwater, $S_{i}$ is the area of the constructed and non-constructed surfaces and $\mathrm{CS}_{\mathrm{i}}$ is the runoff coefficient.

The runoff coefficients used for the standardised model are established according to the standard SR 1846-2:2007, similar to the coefficients established for the surface drainage estimation. Based on the Land Registry no. 203292, district 2, Bucharest, the following runoff coefficients were selected for the constructed and nonconstructed areas: $0.0\left(53,125.79 \mathrm{~m}^{2}\right), 0.05\left(23,976.00 \mathrm{~m}^{2}\right), 0.85\left(175.38 \mathrm{~m}^{2}\right)$ and $0.95\left(1,466.83 \mathrm{~m}^{2}\right)$.

In accordance with the Decision of the Bucharest Local Council (HCLMB acronym from Romanian language) no. 23/1993, the specific quantity of rainwater for the economical operators in Bucharest is:

$$
q S=\cdot 0.5 \frac{m^{3}}{m^{2} \cdot y e a r}
$$




\section{INTERNATIONAL SYMPOSIUM "THE ENVIRONMENT AND THE INDUSTRY", SIMI 2018, PROCEEDINGS BOOK}

The quantity of rainwater drained by the sewerage systems calculated using the standardised model is the following:

$$
A M=0.5 \cdot(53125.79 \cdot 0.0+23976 \cdot 0.05+175.38 \cdot 0.85+1466.83 \cdot 0.95)=1371 \frac{\mathrm{m}^{3}}{\text { year }}
$$

\section{Results and Discussion}

The quantity of rainwater drained by the sewerage systems calculated using the quantitative and the standardised model, is the following:

- $\quad$ Quantitative model which takes into consideration the natural conditions of the site:

o rainwater discharged in the nearby lakes through surface runoff:

$$
\cong 6166.0 \frac{\mathrm{m}^{3}}{\text { year }} \text {; }
$$

o rainwater discharged in the aquifer through groundwater flow:

$$
\cong 4844.0 \frac{\mathrm{m}^{3}}{\text { year }} \text {; }
$$

o rainwater discharged in the sewerage system: $\cong 0.0 \frac{\mathrm{m}^{3}}{\text { year }}$.

- $\quad$ Standardised model: $\cong 1371 \frac{\mathrm{m}^{3}}{\text { year }}$

\section{Conclusions}

It can be concluded that the current practice does not provide a real and precise value for the calculation of the quantity of rainwater drained by the sewerage systems. As a result, the quantity of rainwater obtained through calculations which take into consideration the natural conditions of the sites is significantly lower than the values obtained through the standardised model.

\section{Acknowledgements}

We would like to thank SC Bega Utilaje Constructii SA, the Beneficiary of the current paper for their support during the assessment.

\section{References}

Castany, G 1972, Prospecting and exploitation of groundwater, Technical Publishing House, Bucharest. In French.

Decision of the Bucharest Local Council no. 23/1993 on the approval of the "Indicative Norms for the functioning of the water supply and sewerage systems in Bucharest”.

Ministry Order no. 88 from 20 March 2017 on the approval of the Framework Regulation for the water supply and sewerage services. 
Scradeanu, D \& Gheorghe, A 2007, General Hydrogeology, Ars Docendi Publishing House, Bucharest.

SR 1846-1:2006 Sewages outside the buildings. Design specifications. Part 1: Calculation of sewerage flows.

SR 1846-2:2007 Sewages outside the buildings. Design specifications. Part 2: Calculation of storm water flows. Standard which defines the runoff coefficients for each type of building. 